AUTHOR CONTACT DETAILS

SOCIAL INDICATORS RESEARCH SUBMISSION

\author{
Bruce Headey \\ b.headey@unimelb.edu.au \\ Melbourne Institute of Applied Economic and Social Research \\ University of Melbourne \\ Parkville \\ Australia 3052 \\ Ruud Muffels \\ School of Social and Behavioral Sciences \\ Tilburg University \\ Netherlands \\ Ruud.j.Muffels@Tilburguniveristy.edu
}

\title{
A Theory of Life Satisfaction Dynamics: Stability, Change and Volatility in 25-Year Life Trajectories in Germany
}





\section{A Theory of Life Satisfaction Dynamics: Stability, Change and Volatility in 25-Year Life Trajectories in Germany}

\section{Abstract}

An adequate theory of Life Satisfaction (LS) needs to take account of both factors that tend to stabilise LS and those that change it. The most widely accepted theory in the recent past set-point theory - focussed solely on stability (Brickman and Campbell, 1971; Lykken and Tellegen, 1996). That theory is now regarded as inadequate by most researchers, given that national panel surveys in several Western countries show that substantial minorities of respondents have recorded large, long term changes in LS (Sheldon and Lucas, 2014). In this paper we set out a preliminary revised theory, based mainly on analysis of the LS trajectories of the 2473 respondents in the German Socio-Economic Panel who reported their LS for 25 consecutive years in 1990-2014. The theory entails three sets of propositions in which we attempt to account for stability, change and also volatility. First, it is proposed that stability is primarily due to stable personality traits, and also to parental influence on LS. The second set of propositions indicates that medium and long term changes are due to differences and changes in personal values/life priorities and behavioural choices. Differences in the priority given to pro-social values, family values and materialistic values affect LS, as do behavioural choices relating to one's partner, physical exercise, social participation and networks, church attendance, and the balance between work and leisure. . Medium term change is reinforced by two-way causation - positive feedback loops - between values, behavioural choices and LS. The third set of propositions breaks new ground in seeking to explain inter-individual differences in the volatility/variability of LS over time; why some individuals display high volatility and others low, even though their mean level of LS may change little over 25 years.

Keywords: medium and long term LS change; trajectories of LS; set-point theory; volatility of LS; German Socio-Economic Panel 


\section{INTRODUCTION}

Limitations of set-point theory, trajectories of LS, and the need to develop a theory of change

Set-point theory was probably the most widely accepted empirical theory of LS until recently, and perhaps still is (Brickman and Campbell, 1971; Lykken and Tellegen, 1996). Set-point theory holds that adult LS is stable, primarily due to stable personality traits, notably neuroticism and extroversion. In the last fifteen years or so, the theory has come under increasing challenge as cumulative evidence from national panel surveys showed that substantial minorities of respondents have recorded large, long term changes in LS (Fujita and Diener, 2005; Headey, 2006; Headey, Muffels and Wagner, 2010, 2013). On the basis of this evidence, most contributors to a recent edited volume on set-point theory concluded that its weakness is that it is purely a theory of stability, and that the main priority for LS researchers now should be to develop a theory that also accounts for change (Sheldon and Lucas, 2014).

This paper is mainly based on the $L S$ trajectories of the 2473 respondents in the German Socio-Economic Panel (SOEP) who reported their LS for 25 consecutive years in 1990-2014 (Frick, Schupp and Wagner, 2007). ${ }^{1}$ SOEP is the longest-running panel survey world-wide which provides annual data on LS, so it is the best available dataset on which to base a preliminary theory of change. Long term LS trajectories, now that they are available, provide a rich data source, because they enable us to analyse change at the individual level ('withinperson'). In a pioneering study, using SOEP data, Clark et al (2008) drew graphs of trajectories to show that life events like marital separation and unemployment are anticipated, so that changes in LS often occur, and adaptation may begin, before rather than after an event occurs. Trajectories have also been analysed in research showing that the LS levels of members of the same family tend to covary over time (Winkelmann, 2004; Aguche and Trommsdorff, 2010; Schimmack and Lucas, 2010; Headey, Muffels and Wagner, 2014).

To make the best use of trajectories, it is necessary to go beyond the standard statistical approach of accounting for variance in a vector of LS ratings. Ideally, we want to classify trajectories according to patterns of stability and change over time. However, there is no unique or obviously correct way of classifying them. We have to proceed inductively,

\footnotetext{
${ }^{1}$ Many of the findings reported here have been replicated in other large panel studies, notably the British Household Panel Survey (BHPS), the Household, Income and Labour Dynamics Survey Australia (HILDA), and the Victorian Quality of Life Panel Survey (Headey and Wearing, 1992). Citations to these surveys are included where appropriate.
} 
somewhat by trial and error. In considering how to classify the German LS trajectories, we asked the following questions:

- Long term stability: How many of the 2473 respondents had more or less stable levels of LS, as predicted by set-point theory?

- Long term gains and losses: How many respondents recorded large long term changes in LS between the beginning and end of the 25-year period?

- Medium term gains and losses: Is there evidence of medium term (multi-year) gains and losses, even in cases where LS appears stable in the long term?

- Volatility/variability: How volatile is LS? If there are large between-person differences in the volatility of LS over time, what accounts for these differences?

Attempting to answer these questions gradually led us to arrive at a classification of eight groups of respondents who, in total, comprise $84 \%$ of those on file (i.e. about $16 \%$ had relatively idiosyncratic trajectories and were not classified). We begin the Results section by displaying graphs of the trajectories of eight individuals who are more or less typical of their group either in terms of how much their LS changed in 1990-2014, or in terms of their individual mean and standard deviation of LS over the entire 25-year period (details in the Results section). ${ }^{2}$

One additional pattern observed in the trajectories is that, instead of oscillating around their own long term mean of LS, as set-point theory predicts, most respondents spend several consecutive years above, and in other periods below their own long term mean. In previous papers we reported that these medium term periods of relatively high and relatively low LS appear to be perpetuated by two-way causation - positive feedback loops - between LS and a range of behavioural choices, including taking physical exercise, active social participation and achieving a preferred balance between work and leisure (Headey and Muffels, 2015; 2016).

The theory of LS that we are putting forward is necessarily tentative. It is a preliminary attempt to infer where recent research findings - ours and others - seem to be leading us. The three sets of propositions set out below seek to account for varying trajectories and patterns of stability and change:-

\footnotetext{
${ }^{2}$ Later in the paper we will refer to an individual's mean LS rating for the entire 1990-2014 period as his/her Grand Mean of LS. An individual's standard deviation for the entire period is his/her Grand Standard Deviation.
} 
1. Long term stability, which applies to approximately $61 \%$ of cases in the German file

2.1 Long term change: large gains or losses, which apply to about $24 \%$ of cases

2.2 Medium term change: periods of several consecutive years in which an individual's

LS is above or below his/her own long term mean, and

3. Volatility: inter-individual differences in volatility/variability over the whole time period.

Scope of the theory - not applicable to middle and low income countries

Most LS research has been conducted in Western countries during a period of social and economic stability. y. Previous reviews of this research appear to be based on an assumption (not always explicit) that the causes of LS, although not levels of LS, are the same throughout the Western world (Diener, Suh, Lucas and Smith, 1999; Argyle, 2002). We share this assumption, and expect that the propositions we put forward, although based on German data, will be just about as applicable to other Western countries as to Germany.

In the last decade, there has been an explosion of research on LS in middle and low income countries. Both The World Values Survey and the United Nations, using data from Gallup International, have published LS data on most countries in the world (Inglehart, Foa, Peterson and Welzel, 2008; Deaton, 2008; U.N., World Happiness Reports , 2012-2017). This evidence makes it clear that many propositions which appear to hold true for Western countries do not apply to low and middle income countries. In particular, objective social and economic conditions, which in the West are only modestly correlated with LS, have a strong impact on levels of happiness, and also on inequality of happiness, in lower income countries (Helliwell, Huang and Wang, 2016).

For these reasons it needs to be explicit that the theory outlined here is only intended to apply to Western countries.

\section{Analytic framework and building blocks of theory}

The dependent variables in our preliminary theory, in addition to trajectories, are measures of LS taken over one-year, five-year and 25-year periods (details below). There are five categories of explanatory variables in the theory: individual-level socio-economic variables, personality traits, personal values/life priorities, behavioural choices and health, and domain satisfactions. 
It is necessary to specify the causal sequence in which these variables are assumed to affect LS. A person's socio-economic characteristics and personality traits are treated as causally prior to his/her personal values/life priorities, and so are entered at the first step (first equation) in statistical analyses. Personal values/life priorities are then regarded as causally prior to behavioural choices, which are entered at the second and third steps in statistical models. All of these variables are then regarded as potentially influencing and causally antecedent to domain satisfactions (satisfaction with family, job etc) which are entered at the fourth and final step of statistical models.

In analyses presented in this paper we will only be concerned with the effects of explanatory variables on LS, not on each other. Our preliminary theory would, in principle, be better specified if we formulated hypotheses about intermediate links among explanatory variables, and estimated those links statistically. However, we have left this task for another day.

\section{METHODS}

The German Socio-Economic Panel (SOEP): complete LS records for 1990-2014

SOEP was launched in 1984 in West Germany with a sample of 12,541 respondents (Frick, Schupp and Wagner, 2007). Interviews have been conducted annually ever since. Everyone in the household age 16 and over is interviewed. In order to maintain representativeness, 'split-offs' (e.g. children who leave the parental home to set up their own household) and their new family members (if any) join the panel. The sample was extended to East Germany in 1990, shortly after the Berlin Wall came down, and since then has been boosted by the addition of new immigrant samples, a special sample of the rich, and recruitment of new respondents partly to increase numbers in 'policy groups' (e.g. welfare recipients). There are now over 60,000 respondents on file, including some grandchildren as well as children of the original respondents. The main topics covered in the annual questionnaire are family, income and labour force dynamics. Questions on LS, domain satisfactions (job satisfaction, satisfaction with income etc), health, social participation and exercise have been included every year.

In this paper we analyse data from a balanced panel of respondents $(\mathrm{N}=2473)$ who reported their LS every year during 1990-2014. If we had included all available years of data (19842014), the sample size would have been under 1000, and East Germans would have been excluded. We considered excluding young (e.g. under 25) and old (e.g. over 75) respondents 
on the grounds that the LS of these two groups is believed to be more volatile than for prime age adults (Gerstorf et al 2010). However, results with and without these exclusions were so similar that it seemed preferable to include the entire panel.

It would not be reasonable to claim that the individuals who recorded their LS for 25 consecutive years are a representative sub-set of the entire sample. There is no way of telling. We would speculate that people whose lives are less stable (e.g. due to divorce, unemployment or ill-health) are more likely than average to drop out of the panel. If this is the case, then our results will understate the degree of change and volatility that would have been found in a full, representative sample. What we hope, and it seems plausible, is that the causes and dynamics of change are approximately the same in our sub-sample as in the full panel.

Dependent variables: single and multi-year measures of LS, and individual differences in volatility over time

LS is measured annually on a 0-10 scale ('totally dissatisfied' to 'totally satisfied') with a mean of 6.86 and a standard deviation of 1.72. Single item measures of LS are plainly less satisfactory than the best available multi-item measures, but they are internationally widely used in household panel surveys and have been reviewed as acceptably reliable and valid (Diener, Suh, Lucas and Smith, 1999).

As mentioned, the dependent variables in this paper are in a sense 25-year trajectories of LS. We attempt to detect patterns of stability and change in these trajectories. However, in describing the trajectories of individuals we need to construct some additional multi-year measures of both mean levels of LS, and of volatility/variability over time.

\section{Levels of LS and individual changes up and down the national LS distribution}

The multi-year mean measures of LS that we use are the Grand Mean and 5-year means. An individual's Grand Mean is his/her mean level of satisfaction for 1990-2014. If some or all individuals actually have a LS set-point, then clearly the Grand Mean (or perhaps the Grand Median) would be a candidate for measuring it. We will also use successive 5-year means of LS (1990-94, 1995-1999...2010-14) when we want to summarise the extent to which the LS of individuals has improved, declined or stayed much the same. Using 5-year averages has the advantage of ironing out temporary fluctuations of LS, and is a procedure used in several previous studies of medium or long term stability and change (Fujita and Diener, 2005; 
Headey, Muffels and Wagner, 2010). Changes in LS from one 5-year period to the next may be treated as medium term changes, and changes between the first five years (1990-94) and the last five (2010-14) may be regarded as preliminary evidence about long term change.

The national LS distribution: in order to measure by how much an individual's LS changed, we simply divided the national LS distribution of Germany into percentiles and calculated percentile changes from one period to another.

Volatility of LS - many lives are a wild ride

When one examines graphs of individual LS trajectories, it is immediately clear that some people experience lives that are a wild ride. They are a wild ride in the sense that they experience multiple periods of very high and very low LS, even if (in some cases) their mean level is unchanged in the long term. At the other end of the spectrum, some individuals report much the same level of LS year after year. So, as well as trying to account for differences in levels of LS, we also seek to explain individual differences in volatility/variability over time.

Our main measure of volatility/variability is the Grand Standard Deviation, defined as the standard deviation of an individual's LS measured over 25 years.

Explanatory variables: accounting for stability, change and volatility of $L S$

As previously discussed, five sets of (potentially) explanatory variables will be invoked in accounting for stability, change and volatility of LS: individual socio-economic characteristics, personality traits, values/life priorities, behavioural choices and health, and domain satisfactions.

\section{Socio-economic characteristics}

Reviews of LS research routinely report that a person's socio-economic characteristics have only small effects on his/her LS (Argyle, 2001; Diener et al, 1999). However, it is still sensible to include socio-economic variables in statistical models, if only as 'controls', and to remain alert for possible significant effects on LS. The following variables have been included in all equations underlying results reported in this paper: gender (female $=1$ male $=0$ ), age, age-squared, partner status (partnered=1 not partnered=0), years of education, household wealth (assets minus debts; natural logarithm), household net income (natural logarithm), 
unemployed (unemployed $=1$ other $=0$ ), disability status (disability $=1$ other $=0$ ), East German (East $=1$ other $=0$ ) and foreign (foreign $=1$ German $=0$ ).

\section{Personality traits}

The main personality traits measured in SOEP are the so-called Big Five, which many psychologists regard as adequately describing normal or non-psychotic personality: neuroticism, extroversion, openness to experience, agreeableness and conscientiousness (Costa and McCrae, 1991). Since the traits are partly genetic and quite stable in adulthood (Lykken and Tellegen, 1996; Lucas, 2008), it clearly makes sense to treat them as causally antecedent to LS.

\section{Personal values/life priorities}

Early efforts by LS researchers to measure what have variously been termed values, life priorities, or life goals proved problematic (Andrews and Withey,1976). The SOEP research team tackled the issues afresh and appears to have made considerable improvements in conceptualisation and measurement. Their approach is based on a classification of values developed by Kluckhohn and Strodtbeck (1961). Kluckhohn and Strodtbeck measure three sets of values/priorities:

- pro-social or altruistic values/priorities: friendship, helping others, social and political activism ${ }^{3}$

- family values/priorities: marriage, children and the home

- materialistic values/priorities and career success.

Using this framework, the SOEP team developed survey items which have a stable factor structure and adequate test-retest reliability (Frick, Schupp and Wagner, 2007; Headey, 2008).

\section{Behavioural choices and health}

In previous research, which we reprise here, we have found that changes in LS over time are linked to differences and changes in a range of behavioural choices: choice of partner, active social participation in family and friendship networks, physical exercise, achieving a

\footnotetext{
${ }^{3}$ We use the terms 'pro-social' and 'altruistic' to refer to values which favour behaving cooperatively and helping others. In evolutionary biology altruism is defined as behaviour which involves a loss/cost to the individual concerned, as well as gains to others; we do not imply that here.
} 
preferred balance between work and leisure, and church attendance (Headey, Muffels and Wagner, 2010, 2013; Headey and Muffels, 2015, 2016).

In referring to 'choice of partner', we have in mind partner's personality. Our previous research indicated that partner's personality traits have significant effects on a person's own LS over and above his/her own traits (Headey, Muffels and Wagner, 2010, 2013).

Active social participation and frequency of physical exercise are behavioural choices which also appear related to LS. In SOEP social participation is measured annually with an index which combines two correlated items about frequency of 'meeting with friends, relatives or neighbours' and 'helping out friends, relatives or neighbours'. The response scale has three points: 'every week', 'every month' and 'seldom or never'. The correlation of this index with LS is 0.13 . Frequency of exercise is usually found to be associated with LS, as well as with longevity (Gremeaux et al, 2012). SOEP respondents are asked an annual question about how frequently they engage in active sport or exercise. The response scale runs from 0 ('not at all') to 5 ('every day'). This item's correlation with LS is 0.19 .

The trade-off between paid work (or rather the consumption that work pays for) and leisure is central to welfare economics. It should be mentioned that economists more or less define welfare as LS, although traditionally they have not measured it directly (Frey and Stutzer, 2002). SOEP respondents are asked every year about how many hours per week they actually work (in all jobs combined if they have more than one job), and how many they would prefer to work. The gap between these two figures can be treated as a rough measure of the degree to which they are achieving their preferred trade-off/balance between work and leisure. Individuals who work within plus or minus three hours of their preferred hours are classified as achieving their preferred trade-off/balance. Those who work over three hours more than they want are termed 'overworked', and those who work over three hours less than they want are termed 'underworked'.

It is well known that health has a substantial effect on LS (Diener et al, 1999; Argyle, 2001). SOEP includes a very simple, but internationally widely used health measure on which respondents self-rate their health on a 1-5 scale ('very poor' to 'excellent'). Despite its simplicity, or perhaps because of it, this scale has been assessed as reasonably valid in that it correlates satisfactorily with physician ratings (Schwarze, Andersen and Silke, 2000). Its correlation with LS is 0.38 . 


\section{Domain satisfactions}

A famous Freud quote makes the claim that, "To be happy is to work and to love". Work can offer deep engagement and a sense of accomplishment, and love is often given and received in families. Accordingly, we would expect LS to be strongly affected by two domain satisfactions: job satisfaction and satisfaction with family life. SOEP measures job satisfaction and satisfaction with family life with single questions asked on the same $0-10$ scale as LS ('totally dissatisfied' to 'totally satisfied'). The correlation of job satisfaction with LS is 0.40 , and family life satisfaction correlates 0.46 . Clearly, these correlations are high because the domains are part of life-as-a-whole; one would expect satisfaction with the parts to be closely related to satisfaction with the whole.

Two pioneers in this field, Andrews and Withey (1976) reported that the strongest correlates of LS were not job satisfaction nor satisfaction with family, but satisfaction with the self (see also Ryff, 1989; Headey and Wearing, 1992). The dimensions or aspects of the self which most affected LS, together with typical survey items, were:

(i) a spiritual/meaning dimension: 'the sense of purpose and meaning in your life'

(ii) a moral dimension 'how much you are really contributing to other people's lives'

(iii) a self-development dimension 'the extent to which you are developing yourself and broadening your life'

(iv) an accomplishment dimension 'what you are accomplishing in life', and

(v) a pleasure dimension 'the amount of fun and enjoyment you have'.

These results could be said to hark back to the beliefs of Greek philosophers, particularly Aristotle and the Stoics, about the importance of virtue (including civic virtue) and 'character' to happiness. However, in most contemporary survey research Andrews and Withey's (1976) lead has not been followed, perhaps because questions asking for evaluations of the self seem insufficiently distinct from asking about LS itself. By contrast, researchers working in the relatively new field of positive psychology, who rely mainly on experimental methods rather than surveys, have reported that happiness depends on dimensions similar to those just listed (Lyubomirsky, Sheldon and Schkade, 2005; Seligman, 2011). Probably the best known positive psychology guidelines are Seligman's (2011). He writes that happiness depends on PERMA - positive emotions, engagement, relationships, meaning and accomplishment. Plainly, this list is similar to Andrews and Withey's dimensions. 


\section{Panel effects}

In any panel survey, what are called 'panel conditioning effects' are a possible source of bias. That is, panel members might tend to change their answers over time - and answer differently from the way non-panel members would - as a consequence just of being in a panel. There is evidence that SOEP panel members (like members of other panels) tend to report higher LS ratings in their first few years of responding than they do in later years (Frijters, HaiskenDeNew and Shields, 2004; Headey, Muffels and Wagner, 2013). This could be due to 'social desirability bias'; a desire to look good and appear to be a happy person, which is stronger in the first survey years than later. Or it could perhaps be due to a 'learning effect'; learning to use the middle points of the 0-10 scale, rather than the extremes and particularly the top end.

To compensate for these possible sources of bias, all results are based on equations which include a variable 'controlling' for the number of years panel members have been in the survey.

In summary we have tried to include an appropriate range of explanatory variables and 'controls' which may affect stability, change and volatility in LS. One perhaps strange omission is 'major life events'. There has been a great deal of research on the impact of life events on LS. Most of it has drawn a blank. One thorough investigation concluded that the only reasonably common event which has more than a short term effect on LS is persistent or repeated unemployment (Clark, Diener, Georgellis and Lucas, 2008; Luhmann, Hoffmann, Eid and Lucas, 2012). ${ }^{4}$ A more rare event from which a parent's LS usually never recovers is the death of a child (Wortman and Silver, 1989). We omit life events, not because we necessarily accept the conclusion that they mostly have no impact, but because to challenge it requires detailed assessment of the possible effects of events before, during and after their occurrence; a task too heavy to attempt here.

\section{RESULTS}

Trajectories of LS: 25 years of stability, change and volatility

Figures 1.1-4.2 show the LS trajectories of eight individual respondents for 1990-2014. These individuals recorded trajectories which make them quite typical of eight groups, or eight

\footnotetext{
${ }^{4}$ No event has been conclusively shown to bring a long term increase in LS. A possible candidate, amusingly, is cosmetic surgery (Frederick and Loewenstein, 1999; Wengle, 1986).
} 
patterns, within the total sample of 2473. Trajectories are shown in blue in the Figures, with individual Grand Means in red.

The first two individuals (Figs. 1.1 and 1.2) had LS Grand Means in the top third of the German national distribution. Their Grand Means for 1990-2014 were above 7.75 on the 0-10 scale, and they also recorded means above 7 in each separate five-year period (1990-94, 1995-99...2010-14). The second pair of individuals (Figs. 2.1 and 2.2) had Grand Means in the middle third of the distribution $(>=6.5$ and $<=7.75)$ and five-year means above 6 and below 8 in each five-year period. The third pair had Grand Means in the bottom third of the distribution (under 6.5) and five-year means under 7 in each five-year period. The individuals in each pair differ from each other in the volatility of their LS. The first individual in each pair had a relatively low Grand Standard Deviation for 1990-2014, while the second recorded a relatively high Grand Standard Deviation; the high and low groups being simply split at the mean (i.e. the mean Grand Standard Deviation).

Of course, no six individuals can perfectly represent or typify large groups or patterns of trajectories, but these six all recorded Grand Means and Grand Standard Deviations within 0.1 of the mean results for their sub-set of the sample. ${ }^{5}$

It was more difficult to select individuals whose LS trajectories appear typical of those who recorded large increases in LS (Fig. 4.1) or large declines (Fig. 4.2). In the end, somewhat arbitrarily, we selected cases whose position in the national LS distribution changed by 33.3 percentiles or more between the first and last five-year periods (i.e. 1990-94 to 2010-14). ${ }^{6}$

Overall, the individuals portrayed in Figures 1.1-4.2 may be said to represent $84.4 \%$ of the sample. Levels of LS which appear stable in the long term were recorded by $60.8 \%$ of panel members (Figs. 1.1-3.2), although some had trajectories which were highly volatile in the short and medium term. Of these $60.8 \%, 19.3 \%$ were in the high LS range, $21.6 \%$ in the middle range, and $19.9 \%$ in the bottom range. Substantial long term changes in LS were recorded by $23.6 \%$ of the panel members: $11.5 \%$ recorded increases which placed them 33.3 percentiles or more higher in the national LS distribution in 2010-14 than they had been in 1990-94, and $12.1 \%$ had declined by that amount. That leaves $15.6 \%$ of the sample whose

\footnotetext{
${ }^{5}$ It is of course accepted that different LS trajectories can have the same Grand Mean and Grand Standard Deviation.

${ }^{6}$ It would have made no sense to classify these individuals according to their Grand Standard Deviations as well as their Grand Means, because their Grand Standard Deviations were in all cases large, simply because of their large upward or downward shifts in the distribution over 25 years.
} 
trajectories were relatively idiosyncratic, at least in the sense that they did not fit any of the eight patterns. They included people who experienced just one or two multi-year periods of exceptionally high or low LS (relative to their own Grand Mean) during 1990-2014.

INSERT FIGS. 1.1 - 4.2 HERE

Analysis of LS trajectories, typified in Figures 1.1-4.2, suggest four key overview observations which any adequate theory of LS needs to explain:

(i) Stability/persistence Many people have persistently high levels of LS, while others have persistently low levels.

(ii) Long term change Substantial minorities - but not a majority in Germany - record large, long term changes in LS over 25 years.

(iii) Medium term change Examination of LS trajectories also suggests - and subsequent statistical analysis will confirm - that many people record medium term changes in their levels of LS. Instead of just fluctuating in the short term around their own Grand Mean, as set-point theory claims is 'normal', they spend multiple consecutive years above their Grand Mean, and then in other periods multiple consecutive years below it.

(iv) Volatility/variability The volatility of individual LS varies a great deal. Some individuals maintain much the same level of LS over time, with little variation over one, five, or even 25 years. Other individuals repeatedly experience big gains and falls in LS - their lives are a wild ride - even if there is no long term net change.

We now attempt to characterise each of these main observations more precisely, preparatory to setting out a preliminary theory of LS.

\section{Characterising the frequency of stability/persistence of $L S$}

The pioneers of empirical LS research admitted to two major surprises. They were concerned that happiness might prove to be too fleeting, too evanescent an emotion to be measured validly (Wilson,1967; Bradburn, 1969; Andrews and Withey,1976). Instead they found that individual differences in the frequency and intensity of positive emotions were quite stable 
over time, even when experience sampling methods were used (Diener, Larsen, Levine and Emmons, 1985). Secondly, early LS researchers expected that differences in individuals' social and economic conditions would substantially affect LS (Andrews and Withey, 1976; Campbell, Converse and Rodgers, 1976). Instead they found that, while income and social status had modest effects, their impact was 'surprisingly' small. Levels of education appeared to make almost no difference to LS.

The first well defined empirical theory - adaptation-level theory (Brickman and Campbell, 1971; Easterlin, 1974) - proposed that, far from being fleeting, happiness is almost completely stable. The theory held that we are all on a hedonic treadmill. Favourable and adverse life events can temporarily knock us off the treadmill, but rapid adaptation (habituation) occurs, and we soon revert to our previous baseline level of happiness. Plainly, adaptation-level theory is the lineal ancestor of set-point theory.

Experience-sampling research indicated that most people report being in a good mood most of the time, with fewer than $10 \%$ report being in a bad mood over half the time (Diener, Sandvik and Pavot, 1991; Kahneman et al, 2004). It has been suggested that the human brain is hard-wired for happiness and that nearly all of us are able to modify our perceptions so that we soon come to feel fairly happy with almost any conditions, however apparently adverse (Gilbert, 2006; Wilson and Gilbert, 2008).

Despite this, it is also clear that there are persistent differences between individuals in their levels of LS. Research in the 1970s and 1980s showed that personality traits help to account for different baselines (later termed 'set-points') of LS. Costa and McCrae (1980) showed that neuroticism is quite strongly negatively related to LS, while extroversion is positively related. Since these traits are partly genetic and quite stable in adulthood, they appeared to provide a part-explanation for stable differences. Later in the paper, however, we will find that neuroticism is not just associated with low LS; it is also associated with high volatility (but around a low mean). Research in the 1990s filled out the evidence about links between traits and LS by showing that two other stable traits, agreeableness and conscientiousness, are also positively related to LS (Lucas, 2008).

It is estimated that traits may account for $40-50 \%$ of the variance in LS (Lykken and Tellegen, 1996; Lucas, 2008). However, it is also the case that large numbers of people are persistently more satisfied, and others persistently less satisfied with life than would be 
predicted on the basis of their personality traits alone (Headey, Muffels and Wagner, 2010). So other variables too must play important roles in determining LS.

Parental influence also has long term effects on an individual's LS. The German panel includes a substantial number of parents and children from the same families. In a previous paper, we showed that parental LS has a statistically significant effect on a person's own LS, net of the effects of his/her own personality traits, which are of course genetically linked to parental traits (Headey, Muffels and Wagner, 2014). This influence is strongest while children remain in the parental home (Aguche and Trommsdorff, 2010), but lasts well into adulthood, long after 'children' have left home to set up their own family. So there appears to be a lifelong happiness (or unhappiness) dividend due to parenting. Parents also play an important role in modelling and passing on to their children behaviours which positively affect LS, including taking regular exercise, active participation in social networks, and church attendance (Headey, Muffels and 2014).

Propositions accounting for stability/persistence of LS: stabilising factors

1.1 The personality traits of extroversion, agreeableness and conscientiousness are moderately associated with higher than average long term levels of LS.

1.2 The neuroticism trait is strongly associated with below average long term levels of LS. (But see below; neuroticism is also associated with high volatility).

1.3 Parental LS remains positively related to a person's own LS well into adulthood.

1.4 In Western countries, individual differences in economic circumstances and social status have only small, although statistically significant effects on LS. Levels of education appear to make little difference.

II Characterising change in LS: The frequency and duration of medium and long term change Before setting out propositions to explain changes in LS, more needs to be said about their frequency and duration.

Long term change

In previous papers we showed that about $10 \%$ of respondents in Australian, British and German national panels recorded long term changes which moved them 50 percentiles or 
more up or down their national LS distribution over periods ranging from ten to 25 years (Headey, Muffels and Wagner, 2010, 2013). Over 20\% moved up or down the distribution by 33.3 percentiles or more, and over a third by 25 percentiles or more. In this paper, using data for 1990-2014, we can report that 10.4\% (4.8\% up and 5.6\% down) of German respondents moved up or down the distribution by 50 percentiles or more between the first and last five years of the period. $23.6 \%$ moved by 33.3 percentiles or more (11.5\% up and $12.1 \%$ down), and 35.9\% (17.9\% down and $18.0 \%$ down) moved by 25 percentiles or more.

Another approach to analysing long term change is via $L S$ mobility tables, analogous to income mobility tables. In Table 1 the panel has been divided into LS quintiles (equal groups of $20 \%$, with quintile 5 being the happiest group) ${ }^{7}$ for the 5-year periods 1990-94 and 201014. The table shows the percentage of each starting quintile that ended up in the same or different quintiles in 2010-14. The figures in bold type show percentages that were in the same quintile in the last period, as they had been in the first.

\section{INSERT TABLE 1 HERE}

At first sight, it might seem that the top and bottom quintiles were more stable than the middle three; $45.40 \%$ of those in the top quintile in 1990-94 were there in $2010-14$, and $46.34 \%$ of those in the bottom quintile in the early years were also there at the end. The middle quintiles appear more volatile with $29.05 \%$ ( $2^{\text {nd }}$ quintile), $24.90 \%$ ( $3^{\text {rd }}$ quintile) and $31.32 \%$ ( $4^{\text {th }}$ quintile) remaining in place. However, as readers familiar with income mobility tables will know, these results are somewhat misleading. Individuals who start in the top or bottom quintiles can only move in one direction in later periods, whereas those who start in the middle quintiles can move in either direction. Overall, the Kendall tau-b rank order correlation between LS quintiles in the first and last 5-year periods is a moderate 0.39.

A more dramatic account of LS change, which appears almost to contradict the evidence in Table 1, emerges when we divide panel members into quintiles in each successive five-year period, so that we have five five-year periods overall. It transpires that only $5.18 \%$ of respondents remained in the top quintile for all five periods, and an astonishing $41.52 \%$ were

\footnotetext{
${ }^{7}$ Ties in 5-year LS scores were broken by adding a uniformly distributed variable with a mean of zero and a tiny deviation to each individual's score.
} 
there at least once. Similarly, we find that only $4.79 \%$ were in the bottom quintile for all five periods, while $40.93 \%$ were there at least once.

\section{Medium term change}

Why this apparently contradictory evidence? The explanation comes from considering medium term change. We mentioned earlier that examination of LS trajectories suggests that it may be common for people to spend multiple consecutive years above and, in other periods, below their own Grand Mean. The duration of such changes can be assessed statistically with fixed effects (within-person) longitudinal bivariate regressions in which LS at time $\mathrm{t}$ is the independent variable, and the dependent variables are successively: $\mathrm{LS}$ at $\mathrm{t}+1$ (or $\mathrm{t}-1), \mathrm{t}+2$ (or $\mathrm{t}-2), \mathrm{t}+3$ (or $\mathrm{t}-3$ ), $\mathrm{t}+4$ (or $\mathrm{t}-4), \mathrm{t}+5$ (or $\mathrm{t}-5) .^{8}$ In order to interpret the regression results in Table 2, it is crucial to appreciate that, in fixed effects analyses, coefficients are calculated by relating annual deviations from each individual's own Grand Mean on the dependent variable to annual deviations from his/her Grand Mean on independent variables.

\section{INSERT TABLE 2 HERE}

The coefficients in Table 2 indicate that, if an individual is above his/her own Grand Mean of $\mathrm{LS}$ in a particular year, then $\mathrm{h} / \mathrm{she}$ is more rather than less likely to be above it in each (but, given the size of the coefficients, not all) of the four years beforehand and the four years afterwards (i.e. eight years in total). Similarly, if a person is below his/her grand mean in year $\mathrm{t}$, he/she is likely to be below it for four years before and after.

The results in Table 2 relate to the duration of medium term change. Assessing its frequency requires a different approach. If an individual's LS changed at random from one year to the next, one might expect that $50 \%$ of those who were above their own Grand Mean in year $\mathrm{t}$ would be below it in year $\mathrm{t}+1$, and $50 \%$ would remain above it. If four years of random change occurred only $6.25 \%(50,25,12.5,6.25)$ would be continuously above their own Grand Mean. Similarly, among those individuals who were below their own Grand Mean in year $\mathrm{t}$, random change would see $6.25 \%$ remain below it for all of the next four years. In fact,

\footnotetext{
${ }^{8}$ Each of these 5 pairs of coefficients are bound to be almost exactly the same because, in the overall analysis, variables for each year appear an approximately equal number of times as year $t, t+1, t-1$ etc. There is just a small amount of asymmetry due to the beginning and end years of the 25 -year period.
} 
in the German panel, we find that $31.22 \%$ of those who were above their own Grand Mean in year $\mathrm{t}$ were above it for the next four years, and $15.71 \%$ of those below their Grand Mean in year $\mathrm{t}$ remained so for four years. ${ }^{9}$

Arguably, these results have quite important implications for LS theory. It appears that most people go through quite extended happy periods of life, and also extended unhappy periods. This is contrary to set-point theory, which (as usually understood) only allows for short term fluctuations around a stable mean.

\section{Propositions accounting for medium and long term change in LS}

In setting out propositions about the causes of LS change, we focus on medium and long term change. Short term change is of less interest, and is often due to the temporary effects of life events (Sheldon and Lucas, 2014). Reports of apparent short term change can also be significantly contaminated by current mood (Gaerling and Gamble, 2012).

Research intended to account for medium and long term change is in its infancy. The main variables implicated so far are:-

- Personal values/life priorities

- Choice of partner

- Behavioural choices relating to physical exercise, social participation, the balance between work and leisure, and church attendance

- Changes in health

- Changes in domain satisfactions.

The preferred method of accounting for changes in LS, given panel data, is Generalized Least Squares (GLS) fixed effects (within-person) regression analysis. This method permits relatively strong causal inferences, because all factors affecting the dependent variable, which are fixed within-person over time are automatically netted out ('controlled'). Table 3 gives results accounting for within-person changes in LS from 1990-2014. The dependent variable is annual measures of LS. Explanatory variables are entered in four consecutive steps as outlined in the Methods section: socio-economic variables, personal values/life priorities,

\footnotetext{
${ }^{9}$ The difference between these two figures is at least partly due to the fact that the mean of LS (and hence the Grand Mean) is a little lower than the median (6.96 versus 6.98 on the $0-10$ scale). So, in any given year, a few percentage points more panel members are above their own Grand Mean than below it. Over the entire 25-year period, the same pattern is found. The typical individual recorded a LS rating above his/her own Grand Mean for fourteen years, and was at or below it for eleven years.
} 
health and behavioural choices, and domain satisfactions. Gender, personality traits and other variables which do not change within-person over time are necessarily omitted.

In Table 3 coefficients (bs) are shown only for the first step at which variables were entered into the analysis. So they show the total effect (the direct effect plus the sum of indirect effects) of the explanatory variable in question on changes in LS (Alwin and Hauser, 1975).

\section{INSERT TABLE 3 HERE}

In this balanced panel, age trends in LS are more sharply defined that in most analyses based on cross-sectional data or an unbalanced panel. It can be clearly seen that LS declines steadily with age (see Appendix). This happens all the way from teenage years until shortly before age 60. LS then picks up and remains high even into very old age, indeed until approaching death (Gerstorf et al, 2010). ${ }^{10}$ The trends are much the same for men and women, and increases in LS around age 60 occur both among those who are retired and those who continue in paid work.

The results in column 1 indicate that wealth and income have statistically significant but not large effects in changing LS. However, as Easterlin (2005) has shown, the effects even of large windfall gains are only short term. Most people rapidly habituate even to large changes in wealth or income, so in the narrowly financial domain of life it appears that set-point theory holds. However, this is not true for all economic variables. As mentioned earlier, repeated or long term unemployment has 'scarring' effects from which most individuals never completely recover (Clark, Diener, Georgellis and Lucas, 2008; Luhmann, Hofman, Eid and Lucas, 2012).

It is well known (and unsurprising) that LS usually increases shortly before and after getting married. What is not agreed is whether the effects are only short term, or commonly persist. Several studies report only short term effects (Campbell, Converse and Rodgers, 1976; Clark, Diener, Georgellis and Lucas, 2008), while others suggest that some individuals record long term gains (Lucas, Clark, Georgellis and Diener, 2003; Easterlin, 2005). Our view is that results showing only short term effects are due to a misleading average. We find that

\footnotetext{
${ }^{10}$ Mean LS ratings ( $0-10$ scale) for different age groups are: under 20 years 7.54, 20-29 years 7.22, 30-39 years $6.98,40-49$ years $6.77,50-59$ years $6.67,60-64$ years $6.88,65-69$ years $7.04,70-79$ years 6.93 , age 80 plus 7.00 . The only gender difference is between age 50 and 59: men age 50-54 years 6.68, women age 50-54 years 6.68, men age 55-59 years 6.72, women age 55-59 years 6.64.
} 
partner's personality is crucial in determining whether or not getting married enhances LS (Headey, Muffels and Wagner, 2010). If a person's partner rates low on the neuroticism trait - the trait most strongly related to LS - his/her LS is significantly higher than it would otherwise be. But if partner rates high on neuroticism, one's own long term LS is significantly lowered. The SOEP data indicate that outcomes are almost exactly the same whether people have been married less than 5 years, 5-10 years, 10-20, or more than 20 years. So our view is that the evidence that seemed to show that getting married has only a short term effect was misleadingly based on averaging results for individuals who married relatively neurotic partners with those who married relatively non-neurotic partners.

The SOEP data for 1990-2014 clearly confirm previous research on the long term damage to LS caused by chronic health problems (Mehnert et al, 1990; Lucas, 2007). They indicate that the effects on LS of becoming disabled (an official classification in Germany, not a selfrating) are long term and perhaps more or less permanent. The mean LS of those later classified as disabled began to decline - and declined continuously - for four years before official classification. On average, the decline was from 6.64 on the $0-10$ LS scale to 6.24 in the year in which disability was recognised. Six years later - that is, ten years after the decline began - LS was still substantially below its prior level, although some recovery had occurred (mean $=6.45)$. This result is confirmed by an OLS regression in which the dependent variable is LS six years after the onset of disability. The coefficient of main interest is for the variable 'became disabled in year t' $(b=-0.30 p<0.001)$. This result is net of the effects of LS four years prior to disability, with controls in place for gender, age and age-squared. $^{11}$

Several groups of researchers have shown that giving relatively high priority to materialistic and career values is linked to low long term LS (Nickerson, Schwarz, Diener and Kahneman, 2003; Diener and Seligman, 2004; Headey, 2008). Giving priority to pro-social altruistic values, and also to family values, is linked to higher than average LS. In this context, it has been claimed that human beings have evolved to become caring/nurturant, and that not to care about others is a recipe for unhappiness (de Waal, 2013; Levinson, 1978; Vaillant, 1977). In an interesting experiment, Dunn, Aknin and Norris (2008) showed that subjects who were given money and primed to spend it on others reported higher levels of satisfaction than control group subjects who spent the money on themselves. In the same vein, it has been

\footnotetext{
${ }^{11} \mathrm{LS}_{\mathrm{t}+6}=4.45-0.30$ Disabled $_{\mathrm{t}}+0.42 \mathrm{LS}_{\mathrm{t}-4}-0.06$ Female -0.02 Age +0.03 Age-squared

$\begin{array}{lllll}(0.12) & (0.07) & (0.01) & (0.02) & (0.00)\end{array}$
} 
found that a commitment to volunteering - obviously an activity associated with pro-social values - is linked to high long term LS (Harlow and Cantor, 1996; Thoits and Hewitt, 2001).

In previous papers, we regarded personal values/life priorities as mainly contributing to the stability of LS, rather than change (Headey, Muffels and Wagner, 2010, 2013). This was because the SOEP data show that between-person differences in values are quite stable over time (Headey, 2008). However, the within-person results in Table 3 (col. 2) indicate that values make a modest but statistically significant contribution to LS change. Individuals who change towards giving higher priority to either pro-social values or family values record gains in LS, while those who increasingly prioritise materialistic values record losses.

Changes in materialistic values appear to be associated with ageing. The Pearson correlation between age and the 'importance' given to materialistic values is substantial $(r=-0.36$ $\mathrm{p}<0.001$ ), with the change being particularly marked among people over sixty. A possible interpretation is that the career and material 'rat race' is more or less over for people in this age group, so they tend to prioritise less competitive pro-social and family values. These new results perhaps help to explain why, on average, older people have quite high levels of LS.

It is likely that one reason why giving priority to pro-social and/or family values is more likely to lead to high LS than prioritising materialistic and career values, is that the former are usually non zero sum, whereas the latter are zero sum. Pursuit of materialistic values implies winners and losers; not everyone can do well financially or succeed in the career race. By contrast, pursuit of pro-social and family values is likely to enhance other people's wellbeing, as well as one's own.

Health and behavioural choices relating to exercise, active social participation in family and friendship networks, achieving a preferred balance between work and leisure, and church attendance all have statistically significant effects in changing LS (Table 3, col. 3). The linkages between personal choices and LS are particularly interesting, because they show that we are not all on a hedonic treadmill, with levels of happiness that we are powerless to change. Clearly, some choices are more easily made than others. It is plainly within an individual's power to take more exercise, but becoming more socially active requires the cooperation or acquiescence of others, and working preferred hours usually requires agreement with one's boss. Improvements in health, of course, cannot simply be chosen, but can be attempted through exercise, diet and other lifestyle choices. 
We showed earlier (Table 2) that SOEP respondents typically go through medium term periods in which their LS is either above or below their own long term Grand Mean (for more detail see Headey and Muffels, 2015, 2016). Typically, these extended periods of aboveaverage or below-average LS last for six to eight years. We have explored the possibility that these medium term changes occur in part due to two-way causation - positive feedback loops - between LS and the health and behavioural choice variables in Table 3. Employing a modified form of Granger-causation (Granger, 1969), we estimated two-way causation models which have a close fit with the underlying data, replicating results for SOEP and major Australian and British household panels. To illustrate: some individuals may decide to take more exercise in year $t$. So their LS in year $t+1$ increases. This induces them to continue with their exercise at $t+2$, with the result that their higher level of LS is maintained at $t+3$, and so on. Conversely, a reduction in exercise may set off an extended period of below average LS.

The two-way relationship between health and LS was implied by earlier Dutch longitudinal research, showing that individuals who report low LS live longer than those with lower satisfaction, even controlling for baseline health (Deeg and van Zonneveld, 1989; Diener and Chan, 2011). This could only happen if happiness improves health, or at least slows decline in old age. It is not entirely clear, , however, that the relationship between health and LS is linear. Almost all studies indicate that unhappy people die young, but a few, notably those based on the longitudinal Terman Study of the Gifted, conclude that very happy people may die younger than average, especially if they are somewhat manic (Friedman et al, 1995; Friedman and Martin, 2011).

We have no direct evidence bearing on whether achieving a preferred balance between work and leisure has medium (or long term) effects on LS, rather than just short term. It seems quite likely that the effects are medium term, since in practice the same individuals keep managing to work their preferred hours for several years at a time, while other people are persistently underworked or overworked. The Pearson correlation between working one's preferred hours in year $t$ and $t+1$ is 0.50 , with the five-year correlation being 0.38 .

It has long been known that individuals who report regular religious practice report higher LS than non-religious people, or those who rarely attend religious services (Veenhoven, 2009; Myers, 2013; Headey, Hoehne and Wagner, 2014). Regular church attenders are also somewhat healthier and live longer than the non-religious (Friedman and Martin, 2011; 
Strawbridge, Cohen, Shema and Kaplan, 1997). These findings plainly suggest that the effects of religious practice on LS are long term. It is also clear from the German data that most people who still attend church are mostly from parental families in which attendance was the norm, and have themselves attended all their lives (Headey, Muffels and Wagner, 2014).

The University of Michigan pioneers of LS research found that the variables with the strongest proximate effects on LS are domain satisfactions (Andrews and Withey, 1976; Campbell, Converse and Rodgers, 1976). The final column in Table 3 confirms that individual changes in two domain satisfactions - satisfaction with family life and job satisfaction - have substantial effects in changing LS. It should also be mentioned that several studies have reported two-way causation - positive feedback loops - between LS and satisfaction with one's family (and/or partner), one's job, and evaluations of the self (Headey, Veenhoven and Wearing, 1991; Lance, Mallard and Michalos, 1995; Meier and Stutzer, 2004; Mathison et al, 2007; Nagazato, Schimmack and Oishi, 2011; but see Scherpenzeel and Saris, 1996). So it is reasonably clear that these domain satisfactions contribute to medium term LS.

Propositions accounting for change in LS

2.1 On average, LS declines gradually from about age 20 to about age 60. It then trends upwards when people are in their sixties, and remains high in old age. Trends are the same for men and women.

2.2 Individuals who choose (or are chosen by) partners who rate high on the neuroticism personality trait have lower $L S$ than individuals with partners who rate low on neuroticism. The effects on LS of choice of partner are long term.

2.3 Giving priority to pro-social (altruistic) values is associated with higher than average LS.

2.4 Giving priority to family values is associated with higher than average LS.

2.5 Giving priority to materialistic and career values is associated with lower than average $L S$.

2.6 Individuals who increase their frequency of physical exercise record gains in $L S$. Individuals who decrease their exercise levels show declines in LS. The effects of changing exercise levels are medium term, due to positive feedback loops with LS. 
2.7 Individuals who increase their participation with family and friends in social networks record gains in LS. Individuals who decrease their social participation record declines in $L S$. The effects of social participation are medium term, due to positive feedback loops with $L S$.

2.8.1 Improvements in health are associated with gains in LS. Declining health is associated with declining LS. The effects are medium term, due to positive feedback loops between health and $L S$.

2.8.2 The onset of a chronic health problem, or a physical disability, causes a long term decline in LS. Some adaptation occurs, but it is incomplete.

2.9 Unhappy people die young.

2.10 Achieving a preferred balance between work and leisure is associated with gains in LS. Becoming 'overworked' or 'underworked' is associated with a decline in LS. The effects are usually medium term, because most people's work situation remains the same for several consecutive years.

2.11.1 Being unemployed causes a large decline in LS, but LS typically recovers after an initial period of unemployment.

2.11.2 Repeated or long term unemployment causes a long term decline in LS.

2.12 Gains and losses in satisfaction with family life are associated with gains and losses in LS. The effects are usually medium term.

2.13 Gains and losses in job satisfaction are associated with gains and losses in LS. The effects are usually medium term.

2.14 Changes in satisfaction with (evaluation of) the self are associated with gains and losses in LS. The effects are usually medium term.

III Characterising individual differences in volatility/variability of LS

The volatility of many individual trajectories may come as a shock to LS researchers raised on set-point theory. In this section we document degrees of volatility in more detail, and then seek to account for inter-person variance. Because this is something of a new venture, we do not have specific starting hypotheses, although we expect considerable overlap with the 
variables that account for levels and changes in LS. It will be interesting to see which, if any variables have a greater effect on volatility than they do on levels, and vice-versa.

It may be useful to delineate some differences in volatility. We can divide the panel into thirds - the top, middle and low thirds - as we did in presenting results on levels of LS in Figures $1.1-4.2$.

- The third of the panel in the low volatility range have Grand Standard Deviations ranging from zero to 0.92 with a median of 0.40 .

- The middle third have Grand Standard Deviations ranging from 0.92 to 1.33 with a median of 1.12 .

- The third with the highest volatility have Grand Standard Deviations in the range from 1.34 to 3.40 with a median of 1.76 .

An interesting point is that, in a majority of cases, individuals with high levels of LS record low levels of volatility, while those with low levels record high volatility. A middle group is in-between on both levels and volatility. If LS were a normally distributed variable with a mean of about 5 on the $0-10$ scale, this result would not have been predictable on a priori grounds. However, in practice, LS has a right-side bias; the variable is positively skewed. This makes it unlikely that an individual could have a high enough Grand Mean (over 7.75) to be in the top third of the national LS distribution for the entire period, if he/she also experienced much volatility. A few unhappy years would be possible (see Figs. 1.1 and 1.2), but frequent misfortune not. In fact, the median Grand Standard Deviation of those in the top third was only 0.75 . The middle third recorded a median Grand Standard Deviation of 0.89. In the bottom third of the LS distribution (under 7 in each 5-year period), a high degree of volatility is common; the median is 1.31 . However, those who may be regarded as the most unhappy respondents of all recorded a mean LS under 6 in every five-year period $(5.78 \%$ of the panel), and so had quite low volatility.

Table 4 represents an initial attempt to account for volatility. The sample is restricted to respondents who remained in the same third of the national LS distribution throughout the 25-year period. Respondents who recorded large, long term gains or losses of LS are omitted, because their Grand Standard Deviations are misleading as a measure of volatility. ${ }^{12}$ As before, potential explanatory variables are added to the regression analysis in four steps: (i)

\footnotetext{
${ }^{12}$ They all have high Grand Standard Deviations, not because of volatility, but because of large long term gains or declines in LS.
} 
socio-economic variables and personality traits (ii) plus personal values/life priorities (iii) plus health and behavioural choices, and (iv) plus domain satisfactions. Again, coefficients are reported only for the first equation in which a variable is entered.

Standardised coefficients (Betas) are reported in Table 4. The advantage of reporting Betas, when most variables are measured on arbitrary scales, is that the relative size of coefficients may be treated as a rough measure of the relative 'importance' of variables in accounting for volatility.

\section{INSERT TABLE 4 HERE}

The two variables with the greatest effect on LS volatility are neuroticism (Beta $=0.20$ $\mathrm{p}<0.001)$ and self-reported health (Beta $=-0.17 \mathrm{p}<0.001)$. Finding that neuroticism is strongly related to volatility may seem strange at first reading. How could a personality trait known to be stable in adulthood account for volatility? The explanation would be obvious to a psychologist. Psychologists define neuroticism as 'emotional instability'; a tendency to over-react in potentially stressful situations. Self-reported health is moderately negatively correlated with neuroticism $(\mathrm{r}=-0.22 \mathrm{p}<0.001)$, partly because neurotic people tend to be hypochondriacs. Most people have good health until they become very old, but panel members who suffer, or feel they suffer poor or changeable health record high degrees of volatility.

Wealth (defined as household assets minus debts) is quite strongly negatively related to LS volatility (Beta $=-0.16 \mathrm{p}<0.001)$. This is a particularly interesting result because wealth (like income) is usually found to have only a weak, although statistically significant relationship with levels of LS (Headey, Muffels and Wooden, 2008). So it appears that wealth, while not a major contributor to differences in LS, acts as a protective factor against volatility. This is presumably because people who are relatively wealthy are cushioned against the stresses which would otherwise occur due to declines in labour income or unexpected heavy expenses. 
At the other end of the economic spectrum, unemployment is associated with higher than average LS volatility (Beta $=0.06 \mathrm{p}<0.001$ ). Furthermore, the more often a person was unemployed in this period, the higher was his/her volatility (Beta=0.12 $\mathrm{p}<0.001) .{ }^{13}$

It is usually reported that the number of years of formal education that individuals have received is unrelated to their LS (Diener et al, 1999; Argyle, 2001). So it is interesting to find that education appears to act as a buffer against volatility (Beta $=-0.09 p<0.001)$.

It is well known that partnered/married people are, on average, somewhat happier than those who are single, separated/divorced or widowed. However, the negative relationship in Table 4 between being partnered and LS volatility (Beta $=-0.11 \mathrm{p}<0.001)$ is somewhat stronger than the positive relationship usually found in equations in which the dependent variable is LS levels. ${ }^{14}$ So it appears that being partnered/married, too, is a protective factor against volatility. This result is congruent with evidence that non-partnered people, who may have no-one to turn to in times of stress, are more likely to suffer mental and physical health problems, and to die younger than partnered people (Argyle, 2001; Friedman and Martin, 2011).

Since the end of communism, many East Germans have led severely disrupted lives with both more opportunities and perhaps more problems than before. This is reflected in the finding that they record much higher LS volatility than West Germans (Beta $=0.12 \mathrm{p}<0.001)$.

The evidence in Table 3 already suggested that personal values/life priorities can have modest effects on LS change. Results in Table 4 now indicate that adherence to family values $($ Beta $=-0.07 \mathrm{p}<0.001)$ somewhat reduces volatility, while pursuit of zero sum career and materialistic values increases it $($ Beta $=0.03 \mathrm{p}<0.001)$.

The same behavioural choices that were implicated in affecting LS levels also affect volatility. However, it is interesting that taking regular physical exercise has a stronger effect in reducing volatility than it is usually found to have on levels of LS. So regular exercise appears to be a protective factor against volatility $($ Beta $=-0.09 \mathrm{p}<0.001)$.

Differences in domain satisfactions have substantial effects on volatility. The standardised Betas linking satisfaction with family life and job satisfaction with LS volatility are -0.14

\footnotetext{
${ }^{13}$ The measure here is a simple count of the number of years out of 25 that a person was unemployed.

${ }^{14}$ The coefficient for being partnered is Beta $=0.05(\mathrm{p}<0.001)$ in a parallel equation in which LS is the dependent variable and the explanatory variables are the same as in Table 4.
} 
$(\mathrm{p}<0.001)$ and $-0.11(\mathrm{p}<0.001)$ respectively. As noted earlier, satisfaction with aspects of the self is not measured in the German panel. However, results from an Australian panel survey run in the 1980s indicate that these satisfactions too are negatively related to LS volatility (Headey and Wearing, 1992).

The relationship between age and LS volatility is fascinating. ${ }^{15}$ The highest levels of volatility occurred when panel members were teenagers. This rings true; adolescent and teenage years can be emotionally and behaviourally turbulent. Then from the time respondents were in their twenties until they reached about 70, LS volatility remained quite low, although increasing gradually through these decades. Volatility then increased markedly when panel members were in their seventies and eighties. Overall, the age trend has been the same for men and women. (It may be noted that the two inflection points in the time trend are modelled by including an age-cubed term in equations, in addition to age and age-squared).

Propositions accounting for volatility of $L S$

3.1 LS volatility is at its highest in teenage years. On average, it remains at lower but gradually increasing levels from about age 20 to age 70 . Volatility then increases in old age. The trends are the same for men and women.

3.2 Differences in health are strongly related to LS volatility. Good health is associated with low volatility. Changes in health, with periods of poor health, result in high volatility.

3.3 LS volatility is partly to due to the personality trait of neuroticism. Neuroticism means 'emotional instability'; a tendency to overact in stressful situations.

3.4 Wealth (high net worth) is a protective factor against LS volatility. It enables people to cope better with financial stress, which would otherwise be caused by a decline in labour income or unexpected heavy expenses.

3.5 The more often individuals are unemployed, the greater is their LS volatility.

3.6 Better educated people tend to experience lower LS volatility than people with less formal education.

3.7 Being partnered/married is a protective factor against LS volatility. Single, separated/divorced and widowed individuals record relatively high volatility.

3.8 Regular physical exercise is a protective factor against $L S$ volatility.

\footnotetext{
15 The various age groups recorded the following Grand Standard Deviations: age under 20 1.26, age 20-29 1.14, age 30-39 1.16, age 40-49 1.17, age 50-59 1.19, age 60-69 1.19, age 70-79 1.22, age 80 and over 1.26.
} 
3.9 Domain satisfactions - satisfaction with family, work and aspects of the self-are strongly related to LS volatility. Individuals who maintain high levels of satisfaction in these domains record low volatility. Individuals with changing or low domain satisfactions record high volatility.

\section{DISCUSSION}

We should stress again that the propositions put forward here are only intended to apply to high-income Western countries, not to low and middle income countries. The propositions are a preliminary attempt to envisage where recent research findings, in the wake of set-point theory, are leading us. It is likely that some of the findings we have relied on will be substantially modified or overturned, and new findings and new propositions will come to the fore.

\section{Theories of LS which appear to be false}

Our preliminary theory invokes quite a wide range of explanatory variables: personality traits, personal values (life priorities), behavioural choices, domain satisfactions and socioeconomic characteristics. Like many other social science theories, it could be criticised as 'a bit of this, a bit of that, and a bit of the other'. Maybe so, but in this context it is reasonable to mention alternative theories which once seemed plausible, but which the evidence collected by LS researchers now enables us to reject.

First, there is no evidence that the selfish utility maximiser, enshrined in economics textbooks, has a successful recipe for happiness. On the contrary, individuals who endorse pro-social and/or family values, rather than material and career values, enjoy higher LS. Further, although wealth and income have modest, statistically significant effects on LS, there are many other variables with greater impact.

A second theory which receives little empirical support is hedonism. A hedonist would spend as much time as possible on activities which he/she enjoyed, and as little time as possible on unpleasant activities. So, to test hedonism theory, happiness could be measured as enjoyable time divided by total time. Several research groups have developed measures on these lines and obtained results that are at best ambivalent for hedonism theory (Juster and Stafford, 1995; Kahneman and Riis, 2005). ${ }^{16}$ The population group which typically has the most

\footnotetext{
${ }^{16}$ Neither of these groups of researchers regarded themselves as explicitly testing a theory of hedonism. But, in our view, they developed measures and collected data which provide tests.
} 
discretionary time ('time rich') is single people without children. They are not a particularly happy group. At the other end of the time pressure spectrum ('time poor') are partnered people with children, who also have a full time job. On average, they are happier than the time rich group (Headey and Wearing, 1992; for a different view see Schor,1992).

\section{Implications for set-point theory}

One motivation for trying to develop a revised theory was dissatisfaction with set-point theory, and its hedonic treadmill implication that neither individual choices nor public policy can be expected to make lasting improvements to LS.

Overall, the theory we have put forward paints a quite different picture of typical lifetime trajectories of LS from the one offered by set-point theory. It is suggested that people typically experience extended 'happy' and 'unhappy' periods of life; that is, periods in which their LS is well above or below their own long term mean. A minority record long term, more or less permanent changes in their levels of LS. Both medium and long term changes appear to be substantially due to changes in personal values and behavioral choices which are at least partly subject to personal decision and control.

At this stage, it seems reasonably clear that 'strong' versions of set-point theory (e.g. Brickman and Campbell, 1971; Lykken and Tellegen, 1996), which claim that LS is stable and only subject to short term fluctuations due to life events, have been falsified. Some LS researchers appear to want to rescue 'weak,' more flexible version of the theory in which it is claimed that all individuals who record long run reversion to their Grand Mean more or less 'fit' the theory (see Sheldon and Lucas, 2014, Introduction, chap. 5). In this view, only individuals who record long term, quasi-permanent changes in LS provide evidence contrary to the theory, and perhaps even then the theory could be 'rescued' by claiming that these individuals changed their set-point, rather than acknowledging the possibility that they never had one.

The standard 'positivist' view (accepted here) is that a scientific theory which is 'flexible' is of little value (Popper, 1966). In this view a theory should be brittle, so that if the evidence goes against it, it snaps. ${ }^{17}$ Perhaps set-point theory has snapped. Evidence of long term change and volatility needs explaining not explaining away. In the case of individuals who record high levels of volatility, it may be true, but is nevertheless somewhat perverse, to

\footnotetext{
${ }^{17}$ This particular formulation of positivist theory is due to Robert D. Putnam of Harvard University.
} 
summarise their lives by saying that they revert to a long run mean. Some of the trajectories we have looked at show individuals who have alternated between spending several consecutive years well above their own Grand Mean, and then several below it. Their lives are a wild ride. Only a statistician would summarise by saying, "Fine - but what matters here is reversion to the mean".

The key mechanism underlying set-point theory is adaptation, and there is little doubt that some degree of adaptation is a pervasive human response to changed circumstances (Helson, 1964; Gilbert, 2006). It is probably correct to claim that adaptation to many life events is fast and complete; that is, the individual returns to set-point within a year or so. However, it appears that changes in LS due to behavioural choices - choice of partner, exercise, active participation in social networks, achieving a preferred work-leisure balance, and church attendance - do not fit this pattern. The effects appear to be medium term, in part due to twoway causation - positive feedback loops - between these variables and LS. We do not doubt that, in many cases, some adaptation occurs, but it does not appear to be fast or necessarily complete. So, for example, we would expect that, if a person decides to increase his/her frequency of exercise, this would result in a gain in LS. The initial gain might well be greater than the medium term gain, as adaptation took effect, and eventually the gain might peter out completely. However, it has been suggested that individuals can prevent complete adaptation to desirable life changes by making a conscious effort to continue paying attention to the means by which gains were achieved and the benefits that flow from them (Wilson and Gilbert, 2008; Sheldon and Lucas, chaps. 3-4).

\section{Building a better theory of LS change}

Our main focus has been on personal values/life priorities and behavioural choices which can change LS. We have identified a range of values and choices which make a difference. But it is likely that we have only scratched the surface, and that there are many other variables over which individuals have some degree of control that affect LS. Clearly, the propositions about LS that we have put forward have serious gaps. In particular, we have not offered an account of the tails of the distribution; the 'very happy' and the 'very unhappy' (but see Diener and Seligman, 2002). It is perhaps easy to imagine the reasons for very low LS, or large declines in LS. In some cases mental health problems are involved. Explaining why some people persistently report very high levels of LS, or record big gains and somehow maintain them, is a harder task and one which deserves priority. 


\section{References}

Aguche, A. and Trommsdorff, G. (2010) Transmission of well-being between mothers, fathers and adolescent children: the role of parenting and personality factors, $9^{\text {th }}$ International German Socio-Economic Panel Users Conference, June 30-July 1.

Alwin, D.F. and Hauser, R.M. (1975) The decomposition of effects in path analysis, American Sociological Review, 40, 37-47.

Andrews, F.M. and Withey, S.B. (1976) Social Indicators of Well-Being. New York, Plenum. Argyle, M. (2001) The Psychology of Happiness. London, Routledge.

Bradburn, N.M. (1969) The Structure of Psychological Well-Being. Chicago, Aldine. Brickman, P.D. and Campbell, D.T. (1971) 'Hedonic relativism and planning the good society' in M.H. Appley ed. Adaptation Level Theory. New York, Academic Press, pp. 287-302.

Brickman, P.D., Coates, D. and Janoff-Bulman, R. (1978) Lottery winners and accident victims - Is happiness relative? Journal of Personality and Social Psychology, 36, 917-27.

Campbell, A., Converse, P.E. and Rodgers, W.R. (1976) The Quality of American Life. New York, Sage.

Clark, A.E., Diener, E., Georgellis, Y. and Lucas, R.E. (2008) Lags and leads in Life Satisfaction: A test of the baseline hypothesis, Economic Journal, 118, pp. F222-F243.

Costa, P.T. and McCrae, R.R. (1980) Influences of extroversion and neuroticism on subjective well-being, Journal of Personality and Social Psychology, 38, 668-78.

Costa, P.T. and McCrae, R.R. (1991) NEO PI-R. PAR, Odessa, Fla.

Deaton, A. (2008) Income, health and well-being around the World: Evidence from the Gallup World Poll, Journal of Economic Perspectives, 22, 53-72.

Deeg, D. and van Zonneveld, R. (1989) 'Does happiness lengthen life?' In R.Veenhoven ed. How Harmful Is Happiness? Rotterdam, Erasmus University Press, chap. 5.

de Waal, F. (2013) The Bonobo and the Atheist. New York, Norton. 
Diener, E., Larsen, R.J., Levine, S. and Emmons, R.A. (1985) Intensity and frequency: Dimensions underlying positive and negative affect, Journal of Personality and Social Psychology, 48, 1253-65.

Diener, E., Sandvik, E. and Pavot, W. (1991) 'Happiness is the frequency, not the intensity, of positive versus negative affect' in F. Strack, M. Argyle and N. Schwarz eds. Subjective Well-Being: An Inter-Disciplinary Perspective. New York, Pergamon, pp. 119-39.

Diener, E., Suh, E.M., Lucas, R.E. and Smith, H.L. (1999) Subjective well-being: Three decades of progress, Psychological Bulletin, 25, 276-302.

Diener, E. and Seligman, M.E.P. (2002) Very happy people, Psychological Science, 13, 8184.

Diener, E. and Seligman, M.E.P. (2004) Beyond money: Toward an economy of well-being, Psychological Science in the Public Interest, 5, 1-31.

Diener, E. and Chan, M.Y. (2011) Happy people live longer: Subjective well-being contributes to health and longevity, Applied Psychology: Health and Well-Being, 3, 1-43. doi:10.1111/j.1758-0854.2010.01045.x

Dunn, E.W., Aknin, L.B. and Norton, M.I. (2008) Spending money on others promotes happiness, Science, 319, 1687-88.

Easterlin, R.A. (1974) 'Does economic growth improve the human lot? Some empirical evidence' in P.A. David and M.W. Reder eds. Nations and Households in Economic Growth. New York, Academic Press, pp. 89-125.

Easterlin, R.A. (2005) 'Building a better theory of well-being' in L. Bruni and P. Porta eds. Economics and Happiness: Framing the Analysis. New York, OUP, pp 29-64.

Frederick, S. and Loewenstein, G. (1999) 'Hedonic adaptation' in D. Kahneman, E. Diener and N. Schwarz eds. Well-Being: The Foundations of Hedonic Psychology. New York, Russell Sage, pp.302-29. 
Frey, B.S. and Stutzer, A. (2002) What can economists learn from happiness research? Journal of Economic Literature, 40, 402-35.

Frick, J.R., Schupp, J. and Wagner, G.G. (2007) Enhancing the power of the German SocioEconomic Panel Study (SOEP) - evolution, scope and enhancements, Schmollers Jahrbuch, 127, 139-69.

Friedman , H.S., Tucker, J.S.., Schwartz, J.E., Martin, L.R, Tomlinson-Keasey, C.,Winegard, D.L. and Criqui, M.H. (1995) Childhood conscientiousness and longevity: health behaviors and cause of death, Journal of Personality and Social Psychology, 68, 696-703.

Friedman Friedman, H.S. and Martin, L.R. (2011) The Longevity Project: Surprising Discoveries Health and Long Life from the Landmark Eight-Decade Study. Harmondsworth, Penguin.

Frijters, P., Haisken-DeNew, J.P., and Shields, M.A. (2004) Money does matter! Evidence from increasing real income and life satisfaction in East Germany following reunification, American Economic Review, 94, 730-40.

Fujita, F. and Diener, E. (2005) Life satisfaction set-point: Stability and change, Journal of Personality and Social Psychology, 88, 158-64.

Gaerling, T. and Gamble, A. (2012) Influences on current mood of eliciting life-satisfaction judgments, Journal of Positive Psychology, 7, 219-29.

Gerstorf, D., Ram, N., Hidajat, M., Mayraz, G., Lindenberger, U., Schupp, J. and Wagner, G.G. (2010) Late-life decline in well-being across adulthood in Germany, the UK and the US: Something is seriously wrong at the end of life, Psychology and Aging, $25,477-85$.

Gilbert, D.T. (2006) Stumbling on Happiness. New York, Knopf. 
Gremeaux, V., Gayda, M., Lepers, R, Sosner, P., Juneau, M. and Nigam, A. (2012) Exercise and longevity, Maturitas, 73, 312-17.

Granger, C. W. J. (1969) Investigating causal relations by econometric models and crossspectral methods, Econometrica, 37, 424-38.

Harlow, R. and Cantor, N. (1996) Still participating after all these years: A study of Life Task participation in later life, Journal of Personality and Social Psychology, 71, 1235-49

Headey, B.W., Veenhoven, R. and Wearing, A.J. (1991) Top-down versus bottom-up theories of subjective well-being, Social Indicators Research, 24, 81-100.

Headey, B.W. and Wearing, A.J. (1992) Understanding Happiness: A Theory of Subjective Well-Being. Melbourne, Longman Cheshire.

Headey, B.W. (2006) Subjective well-being: Revisions to dynamic equilibrium theory using national panel data and panel regression methods, Social Indicators Research, 79, 369-403.

Headey, B.W. (2008) Life goals matter to happiness: A revision of set-point theory, Social Indicators Research, 86, 213-31.

Headey, B.W., Muffels, R.J.A. and Wooden, M. (2008) Money does not buy happiness - or does it? A reassessment based on the combined effects of wealth, income and consumption, Social Indicators Research, 87, 65-82.

Headey, B.W., Muffels, R.J.A. and Wagner, G.G. (2010) Long-running German panel survey shows that personal and economic choices, not just genes, matter for happiness, Proceedings of the National Academy of Sciences, 107.42, 17922-17926 (Oct. 19).

Headey, B.W., Schupp, J., Tucci, I. and Wagner, G.G. (2010) Authentic happiness theory supported by impact of religion on life satisfaction: A longitudinal analysis with data for Germany, Journal of Positive Psychology, 5, 73-82.

Headey, B.W., Muffels, R.J.A. and Wagner, G.G. (2013) Choices which change life satisfaction: Similar results for Australia, Britain and Germany, Social Indicators Research, $112,725-48$. 
Headey, B.W., Muffels, R.J.A. and Wagner, G.G. (2014) Parents transmit happiness along with associated values and behaviors to their children: A lifelong happiness dividend? Social Indicators Research, 116, 909-33.

Headey, B.W., Hoehne, G. and Wagner G.G. (2014) Does religion make you healthier and longer lived? Evidence for Germany, Social Indicators Research, 119, 1335-61.

Headey, B.W. and Muffels, R.J.A. (2015) Towards a theory of medium term Life Satisfaction: Two-way causation partly explains persistent satisfaction or dissatisfaction, Social Indicators Research, 124.2. Published online 14 October 2015. DOI 10.1007/s11205015-1146-8.

Headey, B.W. and Muffels, R.J.A. (2016) Towards a theory of medium term Life Satisfaction: Similar results for Australia, Britain and Germany, Social Indicators Research, forthcoming.

Helliwell, J., Layard, R. and Sachs, J. eds. World Happiness Reports (2012-2017). New York, United Nations Sustainable Development Solutions Network.

Helliwell, J., Huang, H. and Wang, S. (2016) 'The distribution of world happiness' in J. Helliwell, R. Layard and J. Sachs eds. World Happiness Report, 2016. New York, United Nations Sustainable Development Solutions Network, chapter 2.

Helson, H. (1964) Adaptation-Level Theory. New York, Harper \& Row.

Inglehart, R., Foa, R., Peterson, C. and Welzel, C. (2008) Development, freedom and rising happiness: a global perspective 1981-2006, Perspectives on Psychological Science, 3, 26485.

Juster, F.T. and Stafford, F.P. (1985) Time, Goods and Well-Being. Ann Arbor, ISR.

Kluckhohn, F.R. and Strodtbeck, F.L. (1961) Variations in Value Orientations. Evanston, Illinois, Row, Peterson.

Kahneman, D., Krueger, A.B., Schkade, D.A., Schwarz, N. and Stone, A.A. (2004) A survey method for characterizing daily life experience: The day reconstruction method, Science, 306 
(5702)1776-80.

Kahneman, D. and Riis, J. (2005) 'Living, and thinking about it: two perspectives on life' in F.A. Huppert, N. Baylis and B. Keverne eds. The Science of Well-Being. Oxford, O.U.P., pp. 285-306.

Lance, C. E., Mallard, A.G. and Michalos, A.C. (1995) Tests of the causal directions of globallife facet satisfaction relationships, Social Indicators Research, 34, 69-92.

Levinson, D.J. (1978) The Seasons of a Man's Life. New York, Knopf.

Lucas, R.E., Clark, A.E., Georgellis, Y. and Diener, E. (2003) Reexamining adaptation and the set point model of happiness: Reactions to change in marital status, Journal of Personality and Social Psychology, 84, 527-39.

Lucas, R.E. (2007) Long-term disability is associated with lasting changes in subjective wellbeing: Evidence from two nationally representative longitudinal studies, Journal of Personality and Social Psychology, 92, 717-30.

Lucas, R.E. (2008) Personality and subjective well-being in M. Eid and R.J. Larsen eds. The Science of Subjective Well-Being. New York, Guilford Press, pp. 171-94.

Luhmann, M., Hofmann, W., Eid, M. and Lucas, R.E. (2012) Subjective well-being and adaptation to life events: A meta-analysis of differences between cognitive and affective well-being, Journal of Personality and Social Psychology, 102, 592-615.

Luhmann, M., Lucas, R.E., Eid, M. and Diener, E. (2013) The prospective effect of life satisfaction on life events, Social Psychological and Personality Science, 4, 39-45.

Lykken, D. and Tellegen, A. (1996) Happiness is a stochastic phenomenon, Psychological Science, 7, 186-89.

Lyubomirsky, S., Sheldon, K.M. and Schkade, D. (2005) Pursuing happiness: 
The architecture of sustainable change, Review of General Psychology, 9, 11131.

Mathison, L., Andersen, M.H., Veenstra, M, Wahl, A.K., Hanestad, B.R. and Fosse, E. (2007) Quality of life can both influence and be an outcome of general health perceptions after heart surgery, Health and Quality of Life Outcomes, 5:27 doi:1186/1477-7525-5-27.

Mehnert, T., Kraus, H.H., Nadler, R. and Boyd, M. (1990) Correlates of life satisfaction in those with a disabling condition, Rehabilitation Psychology, 35, 3-17.

Meier, S. and Stutzer, A. (2004) Is volunteering rewarding in itself? IZA Discussion Paper No 1045 (March) IZA, Bonn.

Myers, D.G. (2013) 'Religious engagement and well-being' in S.A. David, I. Boniwell and A. Conley Ayers eds. The Oxford Handbook of Happiness. Oxford, Oxford University Press, pp. 88-100.

Nagazato, N., Schimmack, U., and Oishi, S. (2011) Effect of changes in living conditions on well-being: A prospective top-down bottom-up model, Social Indicators Research, 100, 11535.

Nickerson, C., Schwarz, N., Diener, E. and Kahneman, D. (2003) Zeroing in on the dark side of the American dream: A closer look at the negative consequences of the goal for financial success, Psychological Science, 14, 531-36.

Popper, K.R. (1966) Objective Knowledge. Oxford, Clarendon Press.

Ryff, C.D. (1969) Happiness is everything, or is it? Explorations on the meaning of psychological well-being, Journal of Personality and Social Psychology, 57, 1069-81.

Scherpenzeel, A. and Saris, W.E. (1996) Causal direction in a model of life satisfaction: The top-down/bottom-up controversy, Social Indicators Research, 38, 161-180.

Schimmack, U. and Lucas, R.E. (2010) Environmental influences on well-being: a dyadic latent panel analysis of spousal similarity, Social Indicators Research, 98, 1-21. 
Schor, J.B. (2002) The Overworked American: The Unexpected Decline of Leisure. New York, Basic Books.

Schwarze, J., Andersen, H. and Silke, A. (2000) Self-rated health and changes in self-rated health as predictors of mortality - first evidence from the German panel data. DIW Discussion Paper No. 203, Berlin, DIW.

Seligman, M.E.P. (2011) Flourish: A Visionary New Understanding of Happiness and WellBeing. New York, Free Press.

Sheldon, K.M. and Lucas, R.E. eds. (2014) The Stability of Happiness. Amsterdam, Elsevier. Strawbridge, W.J., Cohen, R.D., Shema, S.J. and Kaplan, G.A. (1997) Frequent attendance at religious services and mortality over 28 years, American Journal of Public Health, 87.6, 95761.

Thoits, P.A. and Hewitt, L.N. (2001) Volunteer work and well-being, Journal of Health and Social Behavior, 42, 115-31.

Vaillant, G.E. (1977) Adaptation to Life. Boston, Little, Brown.

Veenhoven R. (2009) World Database Of Happiness. Rotterdam, Erasmus University Press. Available at http://worlddatabaseofhappiness.eur.nl/. Accessed May 202016.

Wengle, H. (1986) The psychology of cosmetic surgery: A critical review of the literature, 1960-1982, Part 1, Annals of Plastic Surgery, 16, 435-43.

Winkelmann, R. (2004) Subjective well-being and the family: results from an ordered probit model with multiple random effects, IZA Discussion Paper No. 1016.

Wilson, T.D. and Gilbert, D.T. (2008) Explaining away: A model of affective adaptation, Perspectives on Psychological Science, 3, 370-86.

Wilson, W. (1967) Correlates of avowed happiness, Psychological Bulletin, 67, 294-306.

Wortman, C.B. and Silver, R.C. (1989) The myths of coping with loss, Journal of Consulting and Clinical Psychology, 57, 349-357. 
Figures 1.1-4.2

Trajectories Of LS: Typifying Eight Groups Of Respondents

Fig. 1.1 High Grand Mean,

Low Grand S.D.

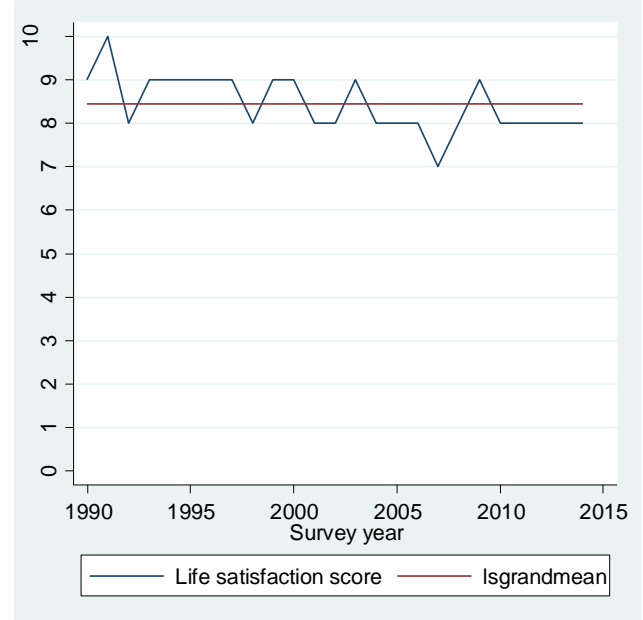

Fig. 2.1 Grand Mean In Mid-Range,

Low Grand S.D.

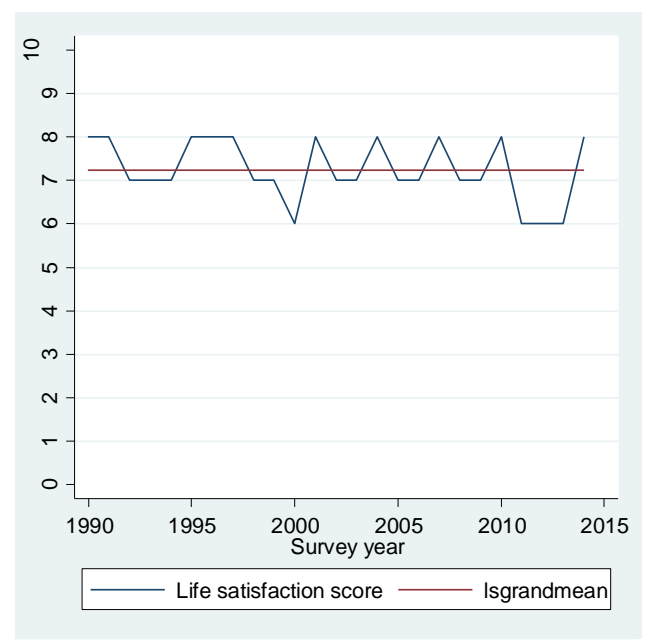

Fig. 1.2 High Grand Mean,

High Grand S.D.

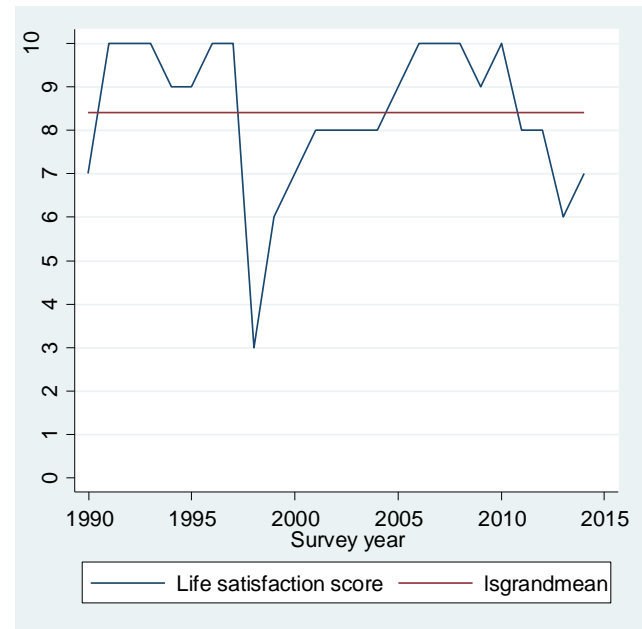

Fig. 2.2 Grand Mean In Mid-Range, High Grand S.D.

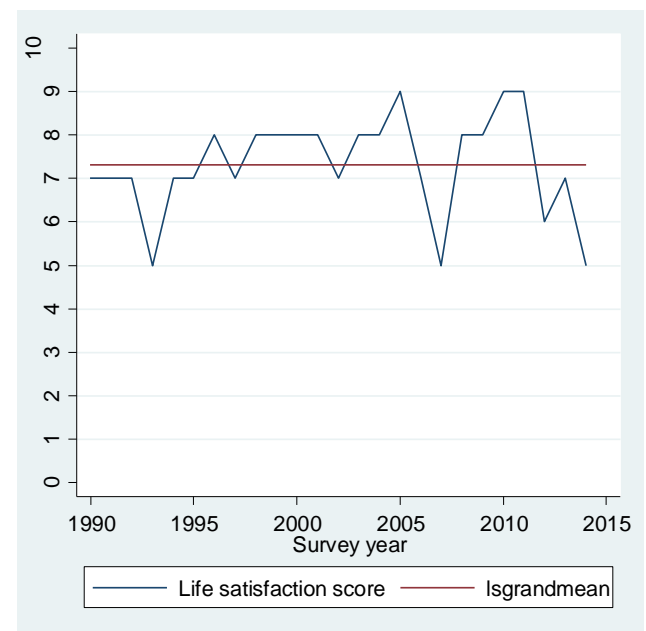


Fig. 3.1 Low Grand Mean,

Low Grand S.D.

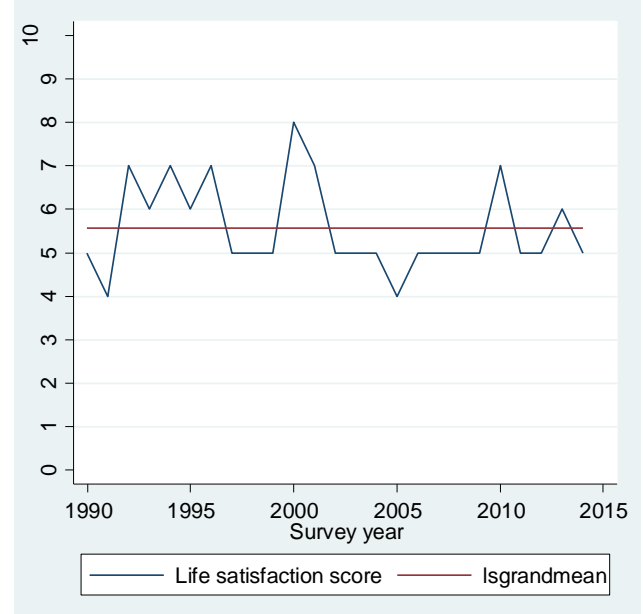

Fig. 4.1 Large Increase In LS

1990-94 to 2010-14

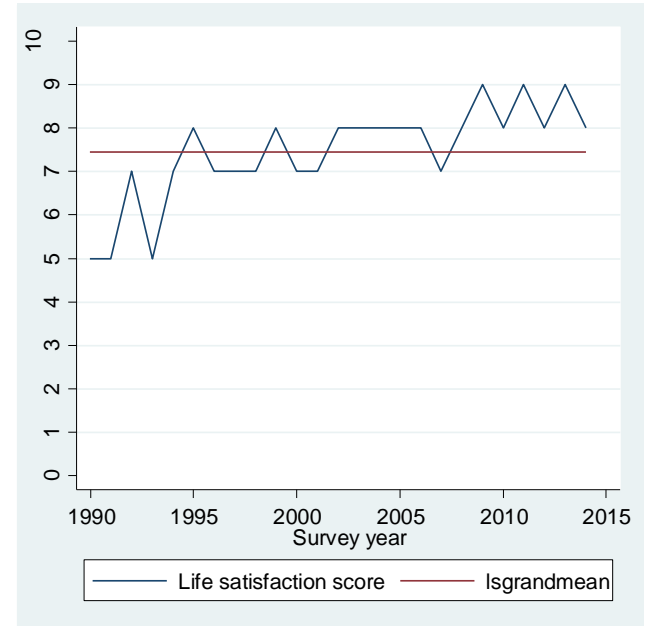

Fig. 3.2 Low Grand Mean,

\section{High Grand S.D.}

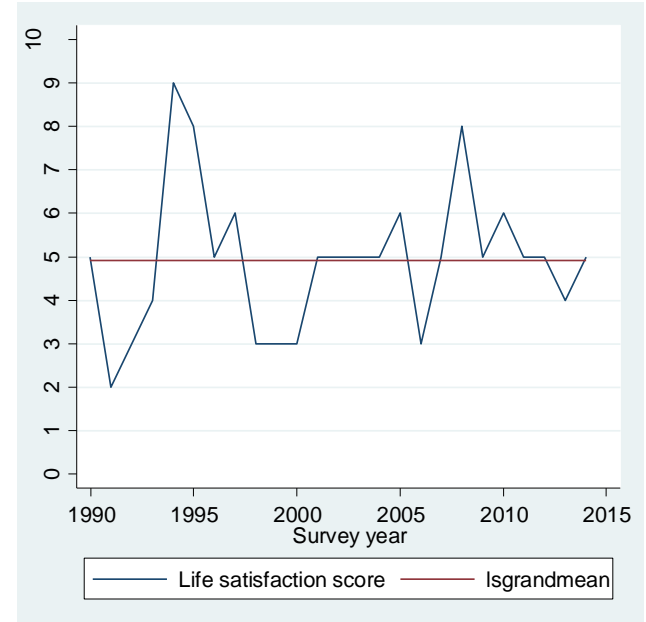

Fig. 4.2 Large Decline in LS

1990-94 to $2010-14$

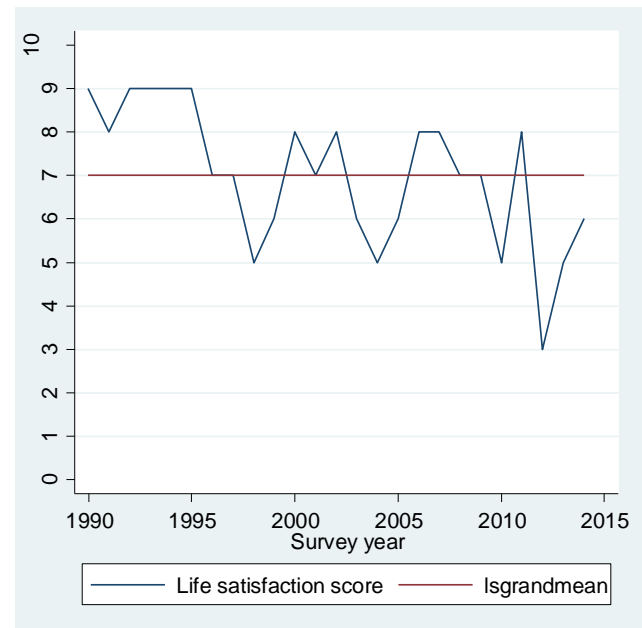


Table 1

LS mobility: Quintiles of LS, 1990-94 to 2010-14

Q1 = lowest level of LS, Q5 = highest level $(\mathrm{N}=2473)^{\mathrm{a}}$

\begin{tabular}{|c|c|c|c|c|c|}
\hline & $\begin{array}{c}Q 11990-94 \\
\%\end{array}$ & $\begin{array}{c}Q 21990-94 \\
\%\end{array}$ & $\begin{array}{c}Q 31990-94 \\
\%\end{array}$ & $\begin{array}{c}Q 41990-94 \\
\%\end{array}$ & $\begin{array}{c}Q 51990-94 \\
\%\end{array}$ \\
\hline$Q 12010-14$ & $\mathbf{4 6 . 3 4}$ & 23.56 & 14.31 & 9.83 & 5.99 \\
\hline$Q 22010-14$ & 25.66 & $\mathbf{2 9 . 0 5}$ & 20.62 & 14.17 & 10.52 \\
\hline Q3 2010-14 & 14.82 & 24.06 & $\mathbf{2 4 . 9 0}$ & 21.04 & 15.12 \\
\hline Q4 2010-14 & 8.37 & 14.29 & 23.11 & $\mathbf{3 1 . 3 2}$ & 22.98 \\
\hline Q5 2010-14 & 4.80 & 9.04 & 17.06 & 23.64 & $\mathbf{4 5 . 4 0}$ \\
\hline & 100.0 & 100.0 & 100.0 & 100.0 & 100.0 \\
\hline
\end{tabular}

a. Source: German Socio-Economic Panel 1990-2014, balanced panel of respondents. 
Table 2

Within-person (fixed effects) bivariate regressions of $\mathrm{LS}_{\mathrm{t}+1}, \mathrm{LS}_{\mathrm{t}-1}$ etc on $\mathrm{LS}_{\mathrm{t}}$ : Metric coefficients with standard errors in parentheses $(\mathrm{N}=59352)^{\mathrm{ab}}$

\begin{tabular}{|c|c|}
\hline Dependent variables & Independent variable \\
& $\mathrm{LS}_{\mathrm{t}}$ \\
\hline $\mathrm{LS}_{\mathrm{t}+1}\left(\right.$ or $\left.\mathrm{LS}_{\mathrm{t}-1}\right)$ & $0.25^{* * *}$ \\
& $(0.004)$ \\
\hline $\mathrm{LS}_{\mathrm{t}+2}\left(\right.$ or $\left.\mathrm{LS}_{\mathrm{t}-2}\right)$ & $0.16^{* * *}$ \\
& $(0.004)$ \\
\hline $\mathrm{LS}_{\mathrm{t}+3}$ (or $\left.\mathrm{LS}_{\mathrm{t}-3}\right)$ & $0.10^{* * *}$ \\
& $(0.004)$ \\
\hline $\mathrm{LS}_{\mathrm{t}+4}$ (or $\left.\mathrm{LS}_{\mathrm{t}-4}\right)$ & $0.05^{* * *}$ \\
& $(0.004)$ \\
\hline $\mathrm{LS}_{\mathrm{t}+5}$ (or $\left.\mathrm{LS}_{\mathrm{t}-5}\right)$ & 0.00 \\
& $(0.004)$ \\
\hline
\end{tabular}

a. Source: German Socio-Economic Panel 1990-2014, balanced panel of respondents.

b. $\mathrm{N}=$ person-years.

*** $\mathrm{p}<0.001$ level 
Table 3

Explaining within-person changes in LS. Fixed effects GLS regressions:

Metric coefficients (bs), standard errors in parentheses $(\mathrm{N}=44797)^{\mathrm{ab}}$

\begin{tabular}{|c|c|c|c|c|}
\hline $\begin{array}{l}\text { Explanatory } \\
\text { variables }\end{array}$ & $\begin{array}{c}\text { Equation } 1 \\
\\
\text { Dependent } \\
\text { variable: } \\
\text { annual } \\
\text { measures of LS } \\
\text { Col (1) } \\
b\end{array}$ & $\begin{array}{c}\text { Equation } 2 \\
\\
\text { Dependent } \\
\text { variable: } \\
\text { annual } \\
\text { measures of LS } \\
\text { Col (2) } \\
b\end{array}$ & $\begin{array}{c}\text { Equation } 3 \\
\text { Dependent } \\
\text { variable: } \\
\text { annual } \\
\text { measures of LS } \\
\text { Col (3) } \\
b\end{array}$ & $\begin{array}{c}\text { Equation } 4 \\
\text { Dependent } \\
\text { variable: } \\
\text { annual } \\
\text { measures of LS } \\
\text { Col (4) } \\
b\end{array}$ \\
\hline \multicolumn{5}{|l|}{$\begin{array}{c}\text { Socio-economic } \\
\text { variables }\end{array}$} \\
\hline Age & $-0.11(0.63)$ & & & \\
\hline Age-squared & $0.03(0.00)^{* * *}$ & & & \\
\hline Married/partnered & $0.17(0.02) * * *$ & & & \\
\hline Years of education & $0.02(0.01)^{* *}$ & & & \\
\hline HH net worth (ln) & $0.02(0.00)^{* * *}$ & & & \\
\hline HH net income $(\ln )$ & $0.08(0.00)^{* * *}$ & & & \\
\hline Unemployed & $-0.59(0.03)^{* * *}$ & & & \\
\hline Disability & $-0.27(0.03)^{* * *}$ & & & \\
\hline Years in panel & $0.06(0.63)$ & & & \\
\hline \multicolumn{5}{|l|}{ Values/life priorities } \\
\hline Pro-social values & & $0.08(0.02)^{* * *}$ & & \\
\hline Family values & & $0.08(0.02)^{* * *}$ & & \\
\hline Materialistic values & & $-0.05(0.02)^{* *}$ & & \\
\hline \multicolumn{5}{|l|}{$\begin{array}{c}\text { Health \& } \\
\text { Behavioural choices }\end{array}$} \\
\hline Health & & & $0.46(0.01)^{* * *}$ & \\
\hline Exercise: frequency & & & $0.03(0.01) * * *$ & \\
\hline Social participation & & & $0.12(0.02)^{* * *}$ & \\
\hline Work-leisure balance & & & $0.07(0.02)^{* * *}$ & \\
\hline Church attendance & & & $0.04(0.01) * *$ & \\
\hline \multicolumn{5}{|l|}{ Domain satisfactions } \\
\hline $\begin{array}{l}\text { Family life } \\
\text { satisfaction }\end{array}$ & & & & $0.20(0.01)^{* * *}$ \\
\hline Job satisfaction & & & & $0.11(0.01)^{* * *}$ \\
\hline
\end{tabular}

a. Source: SOEP 1990-2014, balanced panel of respondents.

b. $\mathrm{N}=$ person-years.

$* * * \mathrm{p}<0.001 * * * \mathrm{p}<0.01 \quad * \mathrm{p}<0.05$ 
Table 4

Explaining between-person differences in LS volatility: Pooled OLS regressions.

Standardised coefficients (Betas) $(\mathrm{N}=37579){ }^{\mathrm{ab}}$

\begin{tabular}{|c|c|c|c|c|}
\hline $\begin{array}{c}\text { Explanatory } \\
\text { variables }\end{array}$ & $\begin{array}{c}\text { Equation } 1 \\
\text { Dependent variable: } \\
\text { individual Grand } \\
\text { Standard Deviation } \\
\text { of LS } \\
\text { Beta } \\
\text { col (1) }\end{array}$ & $\begin{array}{c}\text { Equation } 2 \\
\text { Dependent variable: } \\
\text { individual Grand } \\
\text { Standard Deviation } \\
\text { of LS } \\
\text { Beta } \\
\text { col }(2)\end{array}$ & $\begin{array}{c}\text { Equation } 3 \\
\text { Dependent variable: } \\
\text { individual Grand } \\
\text { Standard Deviation } \\
\text { of LS } \\
\text { Beta } \\
\text { col (3) }\end{array}$ & $\begin{array}{c}\text { Equation } 4 \\
\text { Dependent variable: } \\
\text { individual Grand } \\
\text { Standard Deviation } \\
\text { of LS } \\
\text { Beta } \\
\text { col (4) }\end{array}$ \\
\hline \multicolumn{5}{|l|}{$\begin{array}{c}\text { Socio-economic } \\
\text { variables }\end{array}$} \\
\hline Female & $0.03 * * *$ & & & \\
\hline Age & $1.48 * * *$ & & & \\
\hline Age-squared & $-2.76 * * *$ & & & \\
\hline Age-cubed & $1.35^{* * *}$ & & & \\
\hline Partnered & $-0.11 * * *$ & & & \\
\hline Years of education & $-0.09 * * *$ & & & \\
\hline HH net worth $(\ln )$ & $-0.16 * * *$ & & & \\
\hline HH net income (ln) & $-0.04 * * *$ & & & \\
\hline Unemployed & $0.06 * * *$ & & & \\
\hline Disability & $0.09 * * *$ & & & \\
\hline East German & $0.12 * * *$ & & & \\
\hline Foreign & $0.02 * * *$ & & & \\
\hline Years in panel & $-0.03 * * *$ & & & \\
\hline \multicolumn{5}{|l|}{ Personality traits } \\
\hline Neuroticism & $0.20 * * *$ & & & \\
\hline Partner neuroticism & $0.06 * * *$ & & & \\
\hline Extroversion & $-0.04 * * *$ & & & \\
\hline Openness & $-0.02 * * *$ & & & \\
\hline Agreeableness & $-0.02 * * *$ & & & \\
\hline Conscientiousness & $0.01 * *$ & & & \\
\hline \multicolumn{5}{|l|}{ Values/life priorities } \\
\hline Pro-social values & & 0.00 & & \\
\hline Family values & & $-0.07 * * *$ & & \\
\hline Materialistic values & & $0.03 * * *$ & & \\
\hline \multicolumn{5}{|l|}{$\begin{array}{c}\text { Health \& } \\
\text { Behavioural choices }\end{array}$} \\
\hline Health & & & $-0.17 * * *$ & \\
\hline Exercise: frequency & & & $-0.09 * * *$ & \\
\hline Social participation & & & $-0.02 * * *$ & \\
\hline Work-leisure balance & & & $-0.05 * * *$ & \\
\hline Church attendance & & & $-0.07 * * *$ & \\
\hline \multicolumn{5}{|l|}{ Domain satisfactions } \\
\hline $\begin{array}{l}\text { Family life } \\
\text { satisfaction } \\
\end{array}$ & & & & $-0.14 * * *$ \\
\hline Job satisfaction & & & & $-0.11 * * *$ \\
\hline Adjusted $R$-squared & 0.17 & 0.18 & 0.22 & 0.27 \\
\hline
\end{tabular}

a. Source: SOEP 1990-2014, balanced panel of respondents.

b. $\mathrm{N}=$ person-years.

$* * * \mathrm{p}<0.001 * * \mathrm{p}<0.01 * \mathrm{p}<0.05$ 
Appendix: Age changes in LS
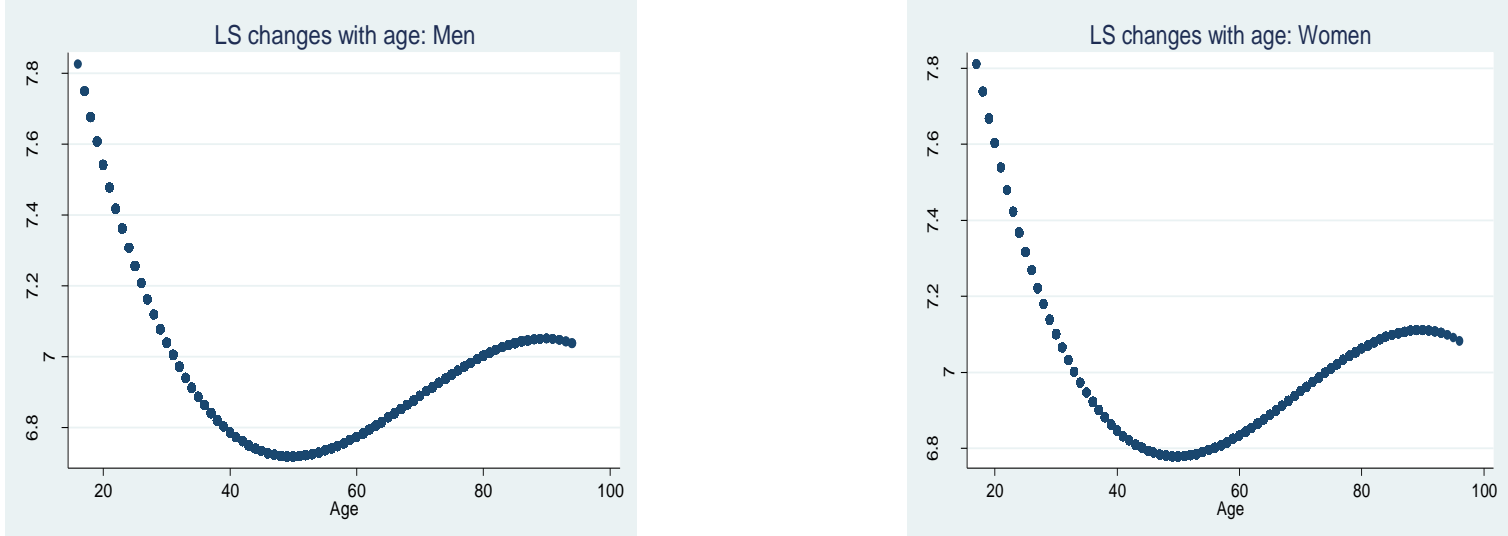


\section{University Library}

\section{- M M N E R VA A gateway to Melbourne's research publications}

Minerva Access is the Institutional Repository of The University of Melbourne

Author/s:

Headey, B;Muffels, R

Title:

A Theory of Life Satisfaction Dynamics: Stability, Change and Volatility in 25-Year Life Trajectories in Germany

Date:

2018-11-01

Citation:

Headey, B. \& Muffels, R. (2018). A Theory of Life Satisfaction Dynamics: Stability, Change and Volatility in 25-Year Life Trajectories in Germany. SOCIAL INDICATORS RESEARCH, 140 (2), pp.837-866. https://doi.org/10.1007/s11205-017-1785-z.

Persistent Link:

http://hdl.handle.net/11343/283286 